\section{Urbanisation and the incidence of eating disorders}

\author{
GABRIËLLE E. VAN SON, DAPHNE VAN HOEKEN, AAD I. M. BARTELDS, \\ ERIC F. VAN FURTH and HANS W. HOEK
}

network of general practitioners coordinated by the Netherlands Institute for Health Services Research (NIVEL), recorded the number of newly diagnosed cases of eating disorders (anorexia nervosa and bulimia nervosa) in their practices during the periods 1985-1989 and 1995-1999. This network, comprising on average 63 general practitioners, served an annual patient load in both periods of about $1 \%$ of the Dutch population. In both periods the population studied was representative of the total Dutch population. For each possible new case of an eating disorder the general practitioner filled out an information sheet, on the basis of which the research team made the final diagnosis. During both study periods the same method was used, the same case-finding information was provided to the general practitioners and the same author (H.W.H.) made the final diagnosis based on DSM-IV criteria (American Psychiatric Association, 1994).

\section{Statistical analysis}

The population under study was divided into three urbanisation levels according to the typology used by the Dutch National Institute of Statistics: rural areas $(20 \%$ or more of the population are involved in agrarian labour), large cities (more than
100000 inhabitants) and urbanised areas (all other areas). The age-adjusted incidence rate ratios for estimating the effect of living in areas with different degrees of urbanisation on the incidence of anorexia nervosa and bulimia nervosa were calculated by Poisson regression analysis (Frome $\&$ Checkoway, 1985) with the use of Stata version 9 for Windows.

\section{RESULTS}

During the two periods a total of 113 patients with anorexia nervosa (107 females and 6 males) and 110 patients with bulimia nervosa (107 females and 3 males) were newly diagnosed. Because there were so few male patients, all further analyses were restricted to data from female patients. The mean age at detection among the latter patients with anorexia nervosa was 22 years (s.d. $=8.1$, median 20 , range 8-57) and among those with bulimia nervosa it was 27 years (s.d. $=8.2$, median 25 , range 13-55). The incidence rate per year per 100000 women-years (age 5-64 years) for anorexia nervosa was $17.4(95 \%$ CI 8.6-23.6) in rural areas, $20.2(95 \% \mathrm{CI}$ $15.6-24.9)$ in urbanised areas and 11.5 (95\% CI 6.2-16.8) in large cities. Bulimia nervosa showed an incidence rate of 7.0 (95\% CI 1.4-12.6) in rural areas, 16.7 (95\% CI 12.5-20.9) in urbanised areas and $25.5(95 \%$ CI 17.7-33.5) in large cities. Table 1 compares the age-adjusted incidence rate ratios of the three urbanisation categories. When the two study periods were analysed separately no time effect was found in the association between urbanisation and incidence.

\section{DISCUSSION}

The main finding of the study was the association of bulimia nervosa incidence with to understanding its aetiology. For several other mental disorders such a link is well established (Sundquist et al, 2004). In 1995 it was first reported that bulimia nervosa is associated with urban life (Hoek et al, 1995). Our study extends this research by adding data collected a decade later. The main question was whether degree of urbanisation constitutes a potential environmental risk factor for eating disorders.

\title{
METHOD
}

In The Netherlands the Continuous Morbidity Registration Sentinel Stations, a

Table I Age-adjusted incidence rate ratio of bulimia and anorexia nervosa by degree of urbanisation in female patients during 1985-1989 and 1995-1999

\begin{tabular}{lcclccc}
\hline Ratio & \multicolumn{2}{c}{ Bulimia nervosa } & & \multicolumn{2}{c}{ Anorexia nervosa } \\
\cline { 2 - 3 } \cline { 5 - 6 } & $\begin{array}{c}\text { Age-adjusted } \\
\text { rate ratio }\end{array}$ & $95 \% \mathrm{Cl}^{\prime}$ & & $\begin{array}{c}\text { Age-adjusted } \\
\text { rate ratio }\end{array}$ & $95 \% \mathrm{Cl}^{\prime}$ \\
\hline Urbanised areas v. rural areas & 2.60 & $1.04-6.49$ & & 0.90 & $0.53-1.54$ \\
Cities v. rural areas & 5.22 & $2.08-13.14$ & & 0.88 & $0.48-1.62$ \\
Cities v. urbanised areas & 2.01 & $1.36-2.97$ & & 0.98 & $0.62-1.54$ \\
\hline
\end{tabular}

I. If the $95 \%$ confidence interval includes $I$, the difference in incidence rates is considered to be non-significant. 
degree of urbanisation in a dose-response fashion. The incidence of bulimia nervosa was almost two and a half times higher in urbanised areas than in rural areas and five times higher in large cities than in rural areas. This is in contrast to the incidence of anorexia nervosa, which showed no association. We conclude that urban life is a potential environmental risk factor for bulimia nervosa but not for anorexia nervosa.

Anorexia nervosa and bulimia nervosa are thought to be closely related disorders and many indications support this view. For example, core features of both disorders concern disturbed eating behaviours, patients tend to migrate between diagnostic categories of eating disorders (Fairburn $\&$ Harrison, 2003) and familial aetiological factors appear to be shared by anorexia nervosa and bulimia nervosa (Strober et $a l, 2000)$. However, living in a large city seems to be strongly associated with the development of bulimia nervosa whereas this is not the case in anorexia nervosa. The dose-response relationship of urbanisation and bulimia nervosa incidence suggests causality. Another indication of the strong environmental influence on the incidence rate of bulimia nervosa is the unstable pattern of the incidence rate over time, as evidenced by the sudden and sharp rise in the incidence of bulimia nervosa since the 1980s (Soundy et al, 1995), the relative rarity of bulimia nervosa before 1970 (Kendler et al, 1991) and the failure to find conclusive evidence of the existence of bulimia nervosa in history (Keel \& Klump, 2003). Such fluctuations in the incidence rate pattern cannot be caused by changing genetic factors because the time scale is too limited.

How can we explain the results? The two main hypotheses are 'migration' and 'opportunity'. In the migration hypothesis it is presumed that adolescents tend to migrate to urban areas, where Dutch educational facilities are principally located. These adolescents might already have developed bulimic symptoms but are 'detected' in the study in the more urbanised areas at an older age. The development of bulimia nervosa would then be independent of living in a large city. However, in the analyses we adjusted for age differences in order to correct this possible effect and the association of urbanisation on the incidence of bulimia nervosa remained. In the opportunity hypothesis the higher incidence

GABRIËLLE E. VAN SON, MA, Centre for Eating Disorders Ursula, Leidschendam, The Netherlands; DAPHNE VAN HOEKEN, PhD, Parnassia Psychiatric Institute, The Hague, The Netherlands; AAD I. M. BARTELDS, MD, Netherlands Institute for Health Services Research (NIVEL), Utrecht, The Netherlands; ERIC F. VAN FURTH, PhD, Centre for Eating Disorders Ursula, Leidschendam and Department of Psychiatry, Leiden University, Leiden, The Netherlands; HANS W. HOEK, MD, PhD, Parnassia Psychiatric Institute, The Hague, Department of Psychiatry, Groningen University, Groningen, The Netherlands and Department of Epidemiology, Columbia University, New York, USA

Correspondence: G. van Son, Centre for Eating Disorders Ursula, PO Box 422, 2260 AK Leidschendam, The Netherlands. Tel: +3I (0)70 444 1444; email: g.vanson@centrumeetstoornissen.nl

(First received 7 April 2006, final revision 13 July 2006, accepted I September 2006)

of bulimia nervosa in large cities is explained by the ability to obtain large amounts of food inconspicuously (Keel \& Klump, 2003). Furthermore, the relative anonymity in large cities makes it easier to engage in secretive behaviour (Hoek et al, 1995). Apart from the opportunity hypothesis, other intra- and interpersonal factors may possibly account for the findings. The interaction of these factors with social aspects of residential areas (such as social cohesion, interpersonal trust and informal social control) might also be of importance as they can have an effect on mental health (Drukker et al, 2003). Further research is needed to elucidate the relationship of bulimia nervosa and urban life. In further studies the residential history of participants should be taken into account along with the time of onset of the bulimic symptoms.

\section{Strengths and limitations of the study}

This study used a registry at primary care level. Therefore, we were able to study a broad patient group, including patients who had never received treatment for their eating disorder. Obtaining data from this level of care is a strength of the study, since only a small and selected proportion of people with eating disorders - mainly patients with anorexia nervosa-are treated by mental health services (Hoek, 2006). A limitation of the study is that we were only aware of the detection date of the disorder, which is not necessarily the same as time of onset. This is also true for the degree of urbanisation; this is only known at time of detection.

\section{ACKNOWLEDGEMENTS}

This research was funded by the Netherlands Ministry of Health. The authors thank the participating general practitioners for their efforts in collecting the data.

\section{REFERENCES}

American Psychiatric Association (1994) Diagnostic and Statistical Manual of Mental Disorders (4th edn) (DSM-IV). Washington, DC: APA.

Drukker, M., Kaplan, C., Feron, F., et al (2003)

Children's health-related quality of life, neighbourhood socio-economic deprivation and social capital. A contextual analysis. Social Science and Medicine, 57, 825-841.

Fairburn, C. G. \& Harrison, P. J. (2003) Eating disorders. Lancet, 36I, 407-416.

Frome, E. L. \& Checkoway, H. (1985) Use of Poisson regression models in estimating incidence rates and ratios. American Journal of Epidemiology, $\mathbf{1 2}$ I 309-323.

Hoek, H.W. (2006) Incidence, prevalence and mortality of anorexia nervosa and other eating disorders. Current Opinion in Psychiatry, 19, 389-394.

Hoek, H. W., Bartelds, A. I. M., Bosveld, J. J. F., et al (1995) Impact of urbanization on detection rates of eating disorders. American Journal of Psychiatry, 152 1272-1278.

Keel, P. K. \& Klump, K. L. (2003) Are eating disorders culture-bound syndromes? Implications for conceptualizing their etiology. Psychological Bulletin, I29, 747-769.

Kendler, K. S., MacLean, C., Neale, M., et al (1991)

The genetic epidemiology of bulimia nervosa. American Journal of Psychiatry, 148, 1627-1637.

Soundy, T. J., Lucas, A. R., Suman, V. J., et al (1995) Bulimia nervosa in Rochester, Minnesota from 1980 to 1990. Psychological Medicine, 25, 1065-1071.

Strober, M., Freeman, R., Lampert, C., et al (2000) Controlled family study of anorexia nervosa and bulimia nervosa: evidence of shared liability and transmission of partial syndromes. American Journal of Psychiatry, I57, 393-401.

Sundquist, K., Frank, G. \& Sundquist, J. (2004) Urbanisation and incidence of psychosis and depression: follow-up study of 4.4 million women and men in Sweden. British Journal of Psychiatry, $\mathbf{1 8 4}$ 293-298.

Weich, S., Twigg, L. \& Lewis, G. (2006) Rural/nonrural differences in rates of common mental disorders in Britain: prospective multilevel cohort study. British Journal of Psychiatry, 188, 5I-57. 